\title{
The Somatosensory Thalamus of the Raccoon: Properties of Single Neurons Responsive to Light Mechanical Stimulation of the Forepaw
}

\author{
Susan Warren, Andrew M. Kelahan, ${ }^{1}$ and Benjamin H. Pubols, Jr. ${ }^{2}$ \\ Department of Anatomy, College of Medicine, The Pennsylvania State University, Hershey, Pennsylvania 17033 , \\ and Neurological Sciences Institute, Good Samaritan Hospital and Medical Center, Portland, Oregon 97209
}

These studies were undertaken to characterize the discharge properties of single neurons of the raccoon thalamic ventrobasal complex (VB) that respond to light mechanical stimulation of the glabrous surfaces of the forepaw. Microelectrodes were used to record the extracellular activity of 146 cells in anesthetized raccoons, and all neurons were histologically verified as falling within or along the boundaries of VB. Sixty-one neurons were tested for activation by electrical stimulaton of primarily somatosensory cortex. Of these, $88 \%$ were antidromically activated, $5 \%$ were synaptically activated, and the remaining $7 \%$ were unresponsive.

Out of the total sample of 146 neurons, 136 had peripheral receptive fields (RFs) that were restricted to glabrous skin and revealed properties of modality and place-specificity predictable through knowledge of properties of primary mechanoreceptive afferents. Rapidly adapting (RA) neurons accounted for $\mathbf{7 7 \%}$ of this modality-place-specific sample, while $19 \%$ were slowly adapting (SA), and 4\% revealed properties indicative of input from Pacinian afferents (Pc). Absolute displacement thresholds were comparable for RA and SA neurons (range $=6-415 \mu \mathrm{m}$ ). Palmar RF areas (range $=3.3-328 \mathrm{~mm}^{2}$ ) were significantly larger than digital RF areas (range $=0.5-98.2 \mathrm{~mm}^{2}$ ).

As defined by exponents (b) of power functions relating instantaneous discharge frequency to displacement ramp velocity, SA neurons formed a single, homogeneous group (range of values of $b=0.633-0.720$ ). However, RA neurons fell into three distinct groups: those showing relatively steep functions $(b-$ $0.559-0.938)$, those showing relatively flat functions $(b=0.146-$ 0.334), and those showing discontinuous, or step, functions.

A small number of neurons ( $7 \%$ of total sample) revealed "complex" properties, not predictable from knowledge of properties of primary afferents. These included five neurons whose RFs encompassed both glabrous and hairy skin, and several linear orientation, or "tactile edge," detectors.

The present results, in conjunction with those of earlier stud-

\footnotetext{
Received Apr. 15, 1985; revised July 31, 1985; accepted July 31, 1985.

We acknowledge the technical assistance of B. J. Pettit, and Susanne D. Dawson. Mark J. Rowinski, John H. Haring, and Helen Louise Pubols each participated in several of the experiments. This study was supported in part by Research Grants NS-13418 and NS-19486, United States Public Health Service. Portions of the data were collected for a dissertation submitted by Susan Warren in partial fulfilment of the requirements for the Ph.D. degree at the Pennsylvania State University.

Correspondence should be addressed to Susan Warren, at her present address: Department of Psychiatry, Washington University School of Medicine, Box 8070, 4940 Audubon Avenue, St. Louis, MO 63110.

1 Present address: Department of Neurology, Northwestern University Medical School, 303 East Chicago Avenue, Chicago, IL 60611.

2 Present address: Neurological Sciences Institute, Good Samaritan Hospital and Medical Center, 1120 N.W. Twentieth Avenue, Portland, OR 97209.

Copyright (C) 1986 Society for Neuroscience $0270-6474 / 86 / 020308-10 \$ 02.00 / 0$
}

ies of the raccoon dorsal column-medial lemniscal system, lead to the conclusion that different types of information transformation are emphasized at different levels of the system. Intramodality convergences (increases in RF area) occur primarily within the cuneothalamic relay, while changes in the coding of quantitative information are primarily a function of VB neurons. The appearance of linear orientation detectors - a type of tactile "feature detector"-indicates that the synthesis of information regarding complex spatial properties of stimuli has its beginnings within the somatosensory thalamus.

The classical modality- and place-specific properties of single neurons of the dorsal column-medial lemniscal system were originally defined by Mountcastle and associates (e.g., Poggio and Mountcastle, 1963; Rose and Mountcastle, 1959) primarily on the basis of studies of the mammalian thalamic ventrobasal complex (VB). More recent studies, using precisely controlled mechanical stimulation (e.g., Golovchinsky et al., 1981), have confirmed that the vast majority of VB neurons display such properties (see Welker, 1973, for a comprehensive review). Ventrobasal neurons have also been shown to be highly precise and reliable in their response to quantitative aspects of mechanical stimulation, such as stimulus indentation depth (Mountcastle, 1967) and velocity (Golovchinsky et al., 1981).

In recent years, it has become apparent that, scattered among these modality-place-specific VB neurons, there are cells displaying other properties, such as large, bilateral receptive fields (RFs; e.g., Berkeley, 1973; Golovchinsky et al., 1976; Jabbur et al., 1972), RFs cncompassing both glabrous and hairy skin (Golovchinsky et al., 1976), and preferential response to stimuli moving laterally across the skin, rather than normal to the skin surface (Golovchinsky et al., 1981; Gordon and Manson, 1967). The proportions of VB neurons showing "complex" properties of the types just described have been variously estimated at between 11\% (Golovchinsky et al., 1981) and 30\% (Jabbur et al., 1972).

The behavioral specialization of the forepaw of the North American raccoon as a tactile organ system (Lyall-Watson, 1963; Welker and Seidenstein, 1959) is associated with enlarged regions of representation of the forepaw, and especially its glabrous surfaces, at all nuclear levels of its somatic afferent system (Welker et al., 1964). Within VB, 50-55\% of the total nuclear volume is devoted to representation of the forepaw. Welker and Johnson (1965) have demonstrated, using both Nissl and Weil staining techniques, that the raccoon VB is composed of a number of subnuclei set off from one another by myelinated fiber laminae, and that adjacent subnuclei contain the "representations" of adjacent regions of the contralateral body surfaces. This fiber lamination and cellular subnucleation is particularly prominent in those ventrobasal regions activated by mechanical 
stimulation of the glabrous skin of the forepaw, both digital and palmar. The relationship between the precise somatotopic organization of the raccoon VB (Welker and Johnson, 1965) and that of its primary somatosensory cortex (Welker and Seidenstein, 1959) has been demonstrated by both retrograde degeneration (Welker and Johnson, 1965), and retrograde HRP transport techniques (Herron, 1983; Warren and Pubols, 1984).

Responses of single tactile neurons to controlled mechanical stimulation of the glabrous surfaces of the raccoon's forepaw have been characterized previously at both the primary afferent (B. H. Pubols and Pubols, 1976; L. M. Pubols and Pubols, 1973; I. M. Pubols et al., 1971) and cuneate nuclear (Haring et al., 1984; Rowinski et al., 1981, 1985) levels. In the present investigation, these studies are extended to single elements of the thalamic VB, most of which are demonstrated, via antidromic activation from primary somatosensory cortex, to be thalamocortical relay (TCR) cells.

\section{Materials and Methods}

\section{Subjects and preparation}

Subjects were 37 adult North American raccoons (Procyon lotor) of either sex, whose body weights ranged between 2.9 and $10.6 \mathrm{~kg}$. Of these, 10 were anesthetized with methoxyflurane (inhalation, $4-8 \%$ in $\mathrm{O}_{2}$ ) and 27 with pentobarbital sodium (initial dose of $40-42 \mathrm{mg} / \mathrm{kg}$, administered intraperitoneally; supplementary doses were administered either intraperitoneally or via the right femoral vein, as needed to maintain surgical depths of anesthesia). The trachea was cannulated and the animal's head mounted in the headholder of a stereotaxic apparatus. Core temperature was monitored and maintained at $36-38^{\circ} \mathrm{C}$.

In all animals, cerebral cortex directly above the right thalamic ventrobasal complex was exposed by removal of overlying scalp and bone. In those cases in which somatosensory cortex was to be electrically stimulated $(N=15)$, the craniotomy was enlarged to allow complete visualization of the somatosensory cortical hand area, and the cisterna magna was opened to allow drainage of cerebrospinal fluid. A dam, either of dental acrylic or of gauze strips soaked in a 3\% agar solution, was constructed around the cortical exposure. After filling the dam with warm paraffin oil, the dura overlying exposed cortex was incised and reflected. In those animals subjected to electrical stimulation of cortex, the left median and ulnar nerves were also exposed at the wrist, dissected free of surrounding tissues, and later placed on bipolar silver wire stimulating electrodes.

The left forepaw was mounted, volar surface up, in silicon impression rubber on an aluminum plate which was rigidly attached to the stereotaxic apparatus. Photographs were taken of the left forepaw, for marking RF boundaries, and of the cortical exposure, for marking the locus of recording microelectrode penetrations and stimulating electrode placements.

\section{Recording technique}

Glass-insulated or varnish-coated tungsten microelectrodes $(0.5-3.0 \mathrm{M} \Omega$ at $135 \mathrm{~Hz}$ ) were used to record the extracellular activity of single ventrobasal neurons. Waveforms were either biphasic (negative-positive) or triphasic (positive-negative-positive), with the negative component having the greatest amplitude (up to $600 \mu \mathrm{V}$ ). With respect to cortical surface topography, most successful penetrations were in the vicinity of the junction of the ansate and lateral fissures, corresponding to HorsleyClarke coordinates $A, 8.0 \pm 1 \mathrm{~mm}$, and $R, 7.5 \pm 1 \mathrm{~mm}$. Recording depths, read in relation to the pial surface, were usually between 14 and $18 \mathrm{~mm}$. Neural activity was appropriately amplified, and monitored via oscilloscope and loudspeaker. Data were stored on analog magnetic tape for subsequent playback and analysis and, in selected cases, oscilloscope traces of neural activity were photographed on line.

\section{Mechanical stimulation}

As the recording microelectrode approached and entered VB, the entire left body surface, including the glabrous surface of the forepaw, was manually stimulated with "search stimuli" such as the experimenter's finger, a glass rod, or a camel hair brush. Upon detecting the presence of mechanically driven activity, more delicate forms of stimulation were utlized. A set of calibrated nylon monofilament von Frey hairs was used to determine, at threshold stimulus intensity, the precise RF locus and boundaries of isolated, single VB neurons; the RF boundaries were carefully plotted on a photograph of each raccoon's hand for subsequent planimetric measurement and analysis of RF areas. Adaptation rate was determined using a suprathreshold monofilament (force $=5 \mathrm{gm}$ ) mounted in a micromanipulator to provide the necessary mechanical stability, and applied to the center of the RF for $10 \mathrm{sec}$ or more. For these determinations, the monofilament was manually lowered onto the skin to provide an indentation of $1000 \mu \mathrm{m}$.

Confirmation of adaptation rate was provided in many instances by a feedback-controlled electromechanical stimulator (Chubbuck, 1966), which was lowered onto the skin at a rate of $100 \mu \mathrm{m} / \mathrm{msec}$. This stimulator was also used for determining absolute displacement thresholds $(N=22)$, and for studying quantitative stimulus-response relationships between stimulus velocity and spike discharge rate during displacement ramp stimulation $(N=17)$. Final skin displacements were either 500 or $1000 \mu \mathrm{m}$, and the range of velocities employed was $0.1-100 \mu \mathrm{m} /$ msec. Between 5 and 10 velocities were employed, and between 5 and 10 trials were given per velocity. Trial length allowed for at least a 2 sec period of maintained displacement following the dynamic (ramp) phase of stimulation, and the intertrial interval varied from unit to unit between 10 and $30 \mathrm{sec}$. The tactile stimulus was a plexiglass probe with a $1 \mathrm{~mm}$ tip diameter, centered over the RF and applied normal to the skin surface.

In a few instances, responses to the initial search stimuli suggested that a neuron might respond preferentially to indentations produced by an edge, rather than by a cylindrical stimulus. In such cases, a handheld or micromanipulator-mounted rod, on the end of which was attached a piece of acetate plastic, $0.3 \mathrm{~mm}$ wide $\times 5.0$ or $7.5 \mathrm{~mm}$ long, was used. These "edge" stimuli were applied normal to the skin surface, both parallel and perpendicular to the long axis of the digit on which the RF was located. Cylindrical stimuli were also applied to these RFs; in each case it was determined if the unit in question did in fact respond preferentially to an edge stimulus and, if so, what the preferred orientation might bc.

\section{Electrical stimulation}

In order to test for antidromic or synaptic activation from primary somatosensory cortex (SmI), digital subgyri of this cortex were electrically stimulated in 61 neurons. For this purpose, a multiple-electrode stimulating device was constructed. It consisted of a perimeter of six electrolytically sharpened stainless steel electrodes surrounding a single central electrode. All electrodes were insulated to within $250 \mu \mathrm{m}$ of the tip with epoxylite varnish. Adjacent perimetric electrodes had a $1 \mathrm{~mm}$ tip separation, and each was $1 \mathrm{~mm}$ from the central electrode. A switching device allowed activation of the central, and any one of the peripheral, electrodes, with either of the pair serving as cathode. All electrodes of the array were inserted into the appropriate subgyrus to a tip depth of approximately $2 \mathrm{~mm}$ (just into the white matter). Using our knowledge of the precise somatotopic organization of each digital subgyrus (Welker and Seidenstein, 1959), as well as of the locus of the RF of the unit under study, it was possible to place the electrode array where stimulation would be most likely to evoke an antidromic response by that thalmic unit. Pairs of stimulating clcctrodes werc testcd scquentially, and absolute thresholds (in $\mathrm{mV}$ ), as well as latencies at $2 \times$ threshold, were recorded at the cathode site which yielded the lowest threshold and shortest latency. If no thalamic responses were obtained with the initial placement of the electrode array, it was successively relocated on SmI cortex until a successful stimulating locus was found. In only four of the tested neurons did we fail to activate the neuron from any cortical electrode placement. Electrical stimuli applied to the cortex were 200 $\mu \mathrm{sec}$ monophasic square waves, $0-10 \mathrm{mV}$ in amplitude, delivered at a rate of $0.5-1.0 \mathrm{~Hz}$.

Criteria for antidromic activation were (1) an all-or-none response consisting of a single spike with a constant short latency of $3.0 \mathrm{msec}$ or less at $2 \times$ threshold, and (2) blocking of the response by collision with an orthodromic spike triggered by electrical stimulation of either the median or the ulnar nerve, or by mechanical stimulation of the ncuron's peripheral RF. In cases where collision was not attempted, the neurons were required to follow a brief, high-frequency $(>100 \mathrm{~Hz})$ pulse train applied to the cortex, in addition to satisfying the latency criteria described above. Neurons responding to cortical stimulation, but not unambiguously meeting the above criteria, were classed as synaptically activated. 


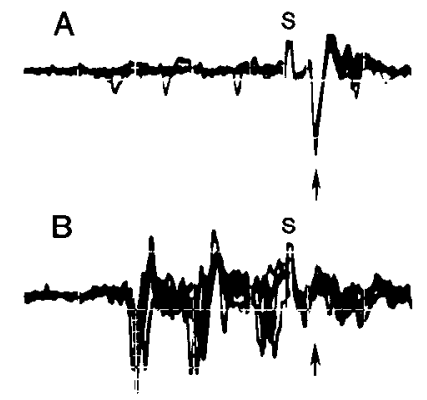

Figure 1. Example of antidromic activation of VB neuron by electrical stimulation of ipsilateral SmI cortex. $A$, Antidromic spike. $B$, Collision by orthodromic spike; orthodromic shock artifact (electrical stimulus to ulnar nerve) off record to left in B. Both records, Length of sweep = $12 \mathrm{msec}$; five superimposed sweeps. $S$. Antidromic stimulus artifact; arrow indicates antidromic spike in $A$, point at which antidromic spike would have occurred if not blocked in $B$. Rapidly adapting unit, RF on digit 5.

\section{Data analysis}

Mechanoreceptive VB neurons were categorized according to their adequate stimulus, rate of adaptation, absolute displacement threshold, RF locus and area, and (where tested) the presence and nature of response to electrical stimulation of SmI. Quantitative data reduction was accomplished via a spike-amplitude discriminator and histogram computer.

\section{Histological reconstruction}

At the termination of each experiment, the subject was perfused transcardially with normal saline followed by a mixture of $10 \%$ formalin with normal saline. In all but five of the brains, thalamic tissue containing electrode tracks was postfixed in $10 \%$ formalin for $24 \mathrm{hr}$ or more. Different blocks of tissue were either celloidin-embedded and sectioned at $30 \mu \mathrm{m}$ on a sliding microtome, or sectioned at $50 \mu \mathrm{m}$ on either a freezing microtome or a Vibratome. All sectioning was in the transverse plane, and all sections were stained either by the Nissl method alone (cresyl violet or thionin), or by Nissl and Weil methods in alternate sections.

Electrode tracks were reconstructed using a projection enlarger, and recording loci were either estimated by interpolation, taking tissue shrinkage into account, or identified relative to microlesions placed in the thalamus during experiments $(5 \mu \mathrm{A}$ for $5 \mathrm{sec})$. All neurons whose properties are described in this paper were found to fall within VB or along its borders.

\section{Results}

Within the raccoon thalamic ventrobasal complex, we have recorded the responses of a total of 146 neurons to mechanical stimulation of the forepaw. Of these, 136 revealed properties of modality and place-specificity (response resulted from stimulation of a relatively discrete receptive field associated with a single morphologically identifiable mechanoreceptor type), predictable from knowledge of the properties of primary mechanoreceptive afferents (B. H. Pubols and Pubols, 1983). These 136 neurons, whose RFs lay entirely on glabrous skin, are characterized in Table 1A. The remaining $10(<7 \%$ of total sample) revealed more complex properties, and their responses to mechanical stimulation will be considered in a separate section. Sixtyone neurons were tested for antidromic or synaptic activation by cortical stimulation. Although not systematically evaluated, it was noted that most neurons displayed a spontaneous discharge, typically consisting of irregularly spaced single spikes or bursts of spikes.

All neurons examined in animals anesthetized with methoxyflurane $(N=34)$ were included in a preliminary report $(\mathrm{B}$. $\mathrm{H}$. Pubols and Warren, 1985), which also included data from 33 neurons from pentobarbital sodium-anesthetized animals. Type of anesthetic had no statistically significant effect on proportions

\section{Table 1}

A. Classification of 136 modality-place-specific VB neurons by modality and type of cortical activation

\begin{tabular}{|c|c|c|c|c|}
\hline \multirow[b]{2}{*}{ Type of cortical activation } & \multicolumn{4}{|c|}{ Modality } \\
\hline & RA & SA & $\mathrm{Pc}$ & Total \\
\hline Antidromic & 36 & 15 & 0 & 51 \\
\hline Synaptic & 3 & 0 & 0 & 3 \\
\hline Not activated & 4 & 0 & 0 & 4 \\
\hline Not tested & 62 & $\underline{11}$ & $\underline{5}$ & 78 \\
\hline Total & 105 & 26 & 5 & 136 \\
\hline
\end{tabular}

B. Percentages of modality-place-specific neurons classed by modality at each of three levels of the somatosensory system

\begin{tabular}{lllrl} 
& \multicolumn{4}{l}{ Modality } \\
\cline { 2 - 5 } Level of system & RA & SA & Pc & Total \\
\hline Ventrobasal complex $(N=136)$ & 77 & 19 & 4 & 100 \\
Main cuneate nucleus $(N=80)^{a}$ & 56 & 24 & 20 & 100 \\
Cuneate fasciculus $(N=313)^{b}$ & 64 & 23 & 13 & 100 \\
\hline
\end{tabular}

"Rowinski et al. (1985).

${ }^{b}$ L. M. Pubols and Pubols (1973).

of VB neurons falling within the several adaptive categories described below (chi-square test; $p>0.50$ ), on absolute displacement thresholds (Mann-Whitney $U$ test; $p=0.60$ ), or on RF areas for units whose RFs were located on either the digits (Mann-Whitney $U$ test; $p=0.18$ ) or the palm pads (MannWhitney $U$ test; $p=0.97$ ). Therefore, in all analyses that follow, data obtained under the two types of anesthetic preparation have been pooled.

\section{Responses to cortical stimulation}

Of the 61 neurons tested, $54(88 \%)$ were antidromically activated from some part of the ipsilateral $\mathrm{SmI}$ hand region; three of these were neurons with complex properties. Three neurons ( $5 \%$ of sample) were synaptically activated, and the remaining four failed to respond to cortical stimulation.

Fifty-one of the antidromically activated neurons were tested for collision by stimulating both the median and ulnar nerves. Of these, 34 were blocked by stimulation of the median nerve, and 17 by stimulation of the ulnar nerve (Fig. 1).

The mean latency to spikc onsct of the antidromically activated neurons was $0.80 \mathrm{msec}$ at $2 \times$ threshold (range $=0.35-$ $3.00 \mathrm{msec}$ ). The mean latency to spike onset for the three synaptically activated neurons was $0.80 \mathrm{msec}$ at $2 \times$ threshold (range $=0.60-1.00 \mathrm{msec}$ ) .

Antidromically activated neurons are classed as thalamocortical relay (TCR) cells. Synaptically activated neurons, as well as those unresponsive to cortical stimulation, may be neurons involved in local thalamic circuitry, neurons projecting to some other nuclear region, or TCR cells that are simply not activated from the particular stimulating electrode placements used.

\section{Categories of modality-place-specific neurons}

The 136 modality-place-specific neurons with peripheral RFs restricted entirely to the glabrous surfaces of the contralateral forepaw (Table 1A) were classified according to the response elicited by a sustained mechanical deformation of the skin. RAs respond only during skin movement, not during static displacement, and have circumscribed RFs. Pcs also respond only transiently, but have larger RF areas, with poorly defined boundaries. Further, they show a more vigorous response to a vibrating $256 \mathrm{~Hz}$ tuning fork applied to the base plate upon which the 


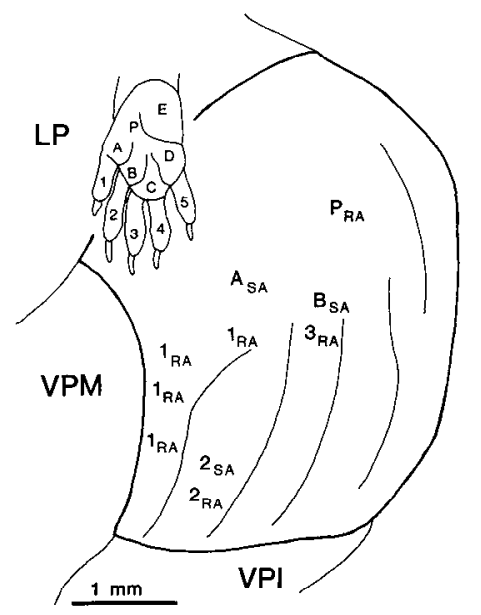

Figure 2. Reconstruction of 10 recording loci obtained in three microelectrode penetrations in right VB of one raccoon. Transverse plane; calibration bar, $1 \mathrm{~mm}$. Lateralmost penetration was actually $1 / 2 \mathrm{~mm}$ posterior to other two penetrations. At each recording locus within VB are indicated the RF locus (inset diagram: key to labeling of digits and palm pads), and, by subscript, whether the unit was rapidly adapting $(R A)$, or slowly adapting $(S A)$. E.g., $1_{R A}=$ rapidly adapting unit with RF on digit 1 . Note orderly somatotopic arrangement in relation to fiber laminae (thin curving lines within VB, whose pars externa is enclosed by thick border), but intermixing within VB of neurons yielding rapidly adapting and slowly adapting responses. No Pacinian $(\mathrm{Pc})$ responses were recorded in this preparation. $L P$, Nucleus lateralis posterior; $V P I$, nucleus ventralis posterior inferior; $V P M$, nucleus ventralis posteromedialis (pars arcuata of VB).

forepaw is mounted than to a 64 or $128 \mathrm{~Hz}$ tuning fork. SA neurons continue to discharge throughout a maintained skin deformation of at least $10 \mathrm{sec}$. There was never any ambiguity in assigning a neuron to one of these three categories.

Approximately $77 \%$ of these modality-place-specific neurons were classed as rapidly adapting, $19 \%$ as slowly adapting, and $4 \%$ as Pacinian. Three of the SA units, all antidromically activated from VB, yielded an "off" response during stimulus retraction. The RA and SA neurons were located in the somatotopically appropriate VB subnucleus, but did not reveal any orderly patterning or grouping with respect to submodality (Fig. 2). In contrast, the Pc units were localized in the ventral regions of VB, or along its ventral border (Fisher et al., 1983). The RF focus was on one of the digital phalanges for two of the Pc units, and on one of the palm pads for the other three.

Table 1B indicates the percentages of modality-place-specific neurons classed as RA, SA, and Pc at each of three levels of the somatosensory system - the thalamic ventrobasal complex, the clusters region of the main cuneate nucleus (MCN; Rowinski et al., 1985), and the cuneate fasciculus (L. M. Pubols and Pubols, 1973). A series of chi-square tests reveals that differences in proportions at the two lower levels are not statistically significant $(p>0.20)$, but that proportions within VB differ from those at the two lower levels $(p<0.01)$. The difference appears as an increase in the proportion of RA units in VB, primarily at the expense of $\mathrm{Pc}$ units, and, to a lesser extent, at the expense of SA units.

\section{Absolute displacement thresholds and receptive-field areas}

Absolute displacement thresholds were obtained using the feedback-controlled electromechanical stimulating system for $17 \mathrm{RA}$ units and 5 SA units. Ramp rise times were either 5 or $10 \mathrm{msec}$, depending upon the unit. Rise time did not appear to affect absolute thresholds in any systematic manner. The median threshold for the RA units was $85 \mu \mathrm{m}$ (range $=15-415 \mu \mathrm{m}$ ), while that for the SA units was $35 \mu \mathrm{m}$ (range $=6-250 \mu \mathrm{m}$ ). The
Table 2. Median RF areas of digital and palmar RFs for ventrobasal nuclear neurons, cuneate nuclear neurons, and cuneate fascicular fibers $^{a}$

\begin{tabular}{lcc} 
& Digits & Palm \\
\hline Ventrobasal complex & 23.2 & 54.0 \\
& $(0.5-98.2)$ & $(3.8-328.1)$ \\
& $N=44$ & $N=37$ \\
Main cuneate nucleus $^{b}$ & 7.8 & 28.5 \\
& $(1.1-54.7)$ & $(6.7-102.8)$ \\
Cuneate fasciculus $^{c}$ & $N=58$ & $N=24$ \\
& 0.17 & 0.28 \\
& $(0.05-2.95)$ & $(0.06-4.50)$ \\
& $N=44$ & $N=16$
\end{tabular}

\footnotetext{
a Areas expressed in $\mathrm{mm}^{2}$; ranges in parentheses.

${ }^{b}$ Rowinski et al. (1981).

${ }^{c}$ L. M. Pubols and Pubols (1973).
}

difference between these median thresholds was not statistically significant (Mann-Whitney $U$ test; $p=0.29$ ).

Threshold RF areas were carefully mapped using nylon monofilament von Frey hairs for 44 neurons with digital RFs and 37 with palmar RFs. The forces exerted varied between ca. $25 \mathrm{mg}$ and $1.2 \mathrm{gm}$; corresponding monofilament diameters ranged between ca. 100 and $200 \mu \mathrm{m}$. Tables 2 gives the medians and ranges for digital and palmar RFs separately, along with the corresponding data for digital and palmar RFs of the clusters region of the MCN (Rowinski et al., 1981), and for the primary afferents of the cuneate fasciculus (L. M. Pubols and Pubols, 1973). Only RF areas of RA and SA neurons are included in this table. Results of a series of Mann-Whitney $U$ tests revealed that (1) digital RF areas do not differ significantly for RA versus SA neurons within VB $(p=0.06)$; (2) palmar RF areas do not differ significantly for RA versus SA neurons within VB $(p=$ 0.30 ); however, (3) within the VB sample, palmar RFs are significantly larger than digital RFs $(p<0.001)$; (4) digital RFs of VB neurons are significantly larger than digital RFs of MCN neurons (ca. $3 \times ; p<0.001$ ); and (5) palmar RFs of VB neurons are also significantly larger than those of $\mathrm{MCN}$ neurons (ca. $2 \times$; $p<0.01)$.

\section{Discharge patterns during displacement ramp stimulation}

When suprathreshold stimuli are applied to a receptive field, the number of spikes emitted during displacement ramp stimulation varies with ramp velocity. When a final displacement of $1000 \mu \mathrm{m}$ was used, SA units began to discharge consistently at a lower velocity $(0.1 \mu \mathrm{m} / \mathrm{msec}$ or less) than did RA units $(M=1.0 \mu \mathrm{m} / \mathrm{msec})$. Once this threshold was reached, the relationship between ramp velocity and number of spikes emitted varied from unit to unit. The most common pattern found in a sample of 12 RA units was one in which the relationship was essentially flat, or exhibited a moderate decrease with increasing ramp velocity (Fig. $3 A$ ). In no instance was there an increasing relationship, as is often seen in primary afferents (Iggo and Ogawa, 1977; Knibestöl, 1973; B. H. Pubols, 1980). In two of five SA units, a bow-shaped pattern was found (Fig. $3 B$ ), and in three SA units a decreasing function was obtained.

For a given displacement velocity (e.g., $10 \mu \mathrm{m} / \mathrm{msec}$ ), the typical discharge pattern during ramp stimulation of both RA and SA units is one of deceleration in discharge rate (seven out of nine RA units; four out of five SA units), or a constant rate throughout the ramp (Fig. 4). These findings are in agreement with previously published data on RA units at both the primary afferent (B. H. Pubols and Pubols, 1983) and cuneate nuclear (Rowinski et al., 1985) levels, but are at variance with regard 

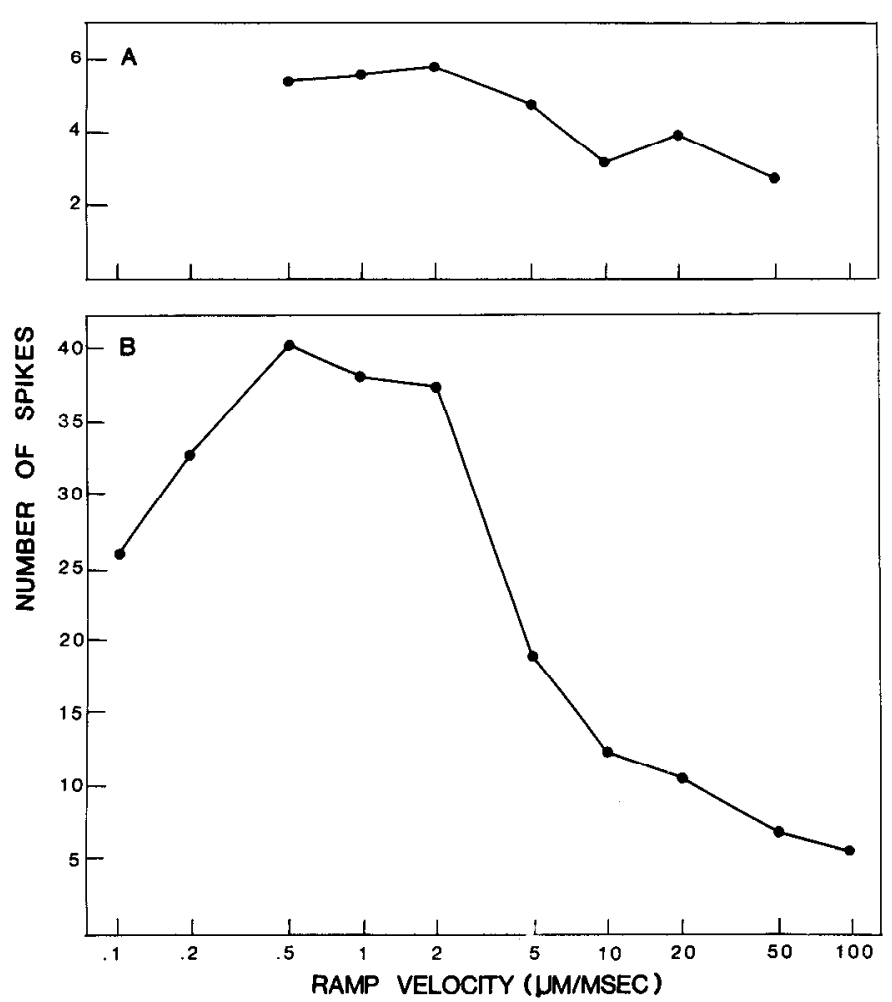

Figure 3. Relationship between indentation ramp velocity and number of spikes emitted during displacement ramp stimulation for two VB units. $A$. RA unit, moderately decreasing relationship. $B$. SA unit, bowshaped relationship. Final displacement $=1000 \mu \mathrm{m}$ in both cases.

to the discharge pattern of SA units at these two levels, where an acceleration of discharge is usually observed.

\section{Discharge rate as a function of displacement ramp velocity}

Discharge rate is commonly expressed as instantaneous frequency $(1000 /$ mean interspike interval; B. H. Pubols and Pubols, 1983). The relationship between discharge rate and displacement ramp velocity was studied in $12 \mathrm{RA}$ units and five SA units (Table 3). For the SA units, the velocity range examined was $0.1-100 \mu \mathrm{m} / \mathrm{msec}$, while for the RA units, the range was between $0.5-100$ and $5.0-100 \mu \mathrm{m} / \mathrm{msec}$. The SA units behaved
RA

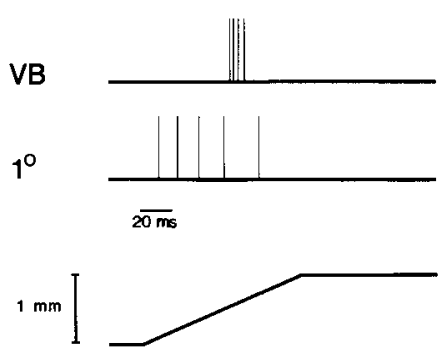

SA

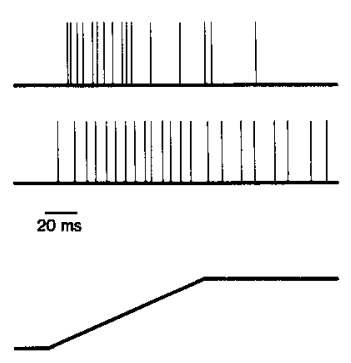

Figure 4. Discharge pattern during displacement ramp stimulation. For a given displacement ramp velocity (e.g., $10 \mu \mathrm{m} / \mathrm{msec}$ in all four cases), the pattern of discharge of both RA and SA thalamic units (upper, left and right, respectively) typically is one of deceleration or constant discharge rate. This is the usual pattern for primary afferent RA units (middle, left), but the acceleration of discharge rate during ramp stimulation characteristic of primary afferent SA units (middle, right) was rarely observed in slowly adapting VB units. Lower, Stimulus displacement traces.
Table 3. Exponents $(b)$ of the power function relating mean instantaneous frequency to displacement ramp velocity, and associated correlation coefficients $(\boldsymbol{r})^{a}$

\begin{tabular}{lllll} 
Unit & RF locus & $\begin{array}{l}\text { Best-fitting } \\
\text { function }\end{array}$ & $b$ & $r$ \\
\hline Slowly adapting & & & & \\
83-15-1A & Digit & Power & 0.633 & 0.963 \\
83-21-3C & Palm & Power & 0.672 & 0.981 \\
81-3-4A & Digit & Power & 0.682 & 0.978 \\
83-20-8B & Digit & Power & 0.702 & 0.978 \\
81-28-1A & Palm & Power & 0.720 & 0.973
\end{tabular}

Rapidly adapting, flat relationship

$\begin{array}{lllll}80-31-2 D & \text { Digit } & \text { Power } & 0.146 & 0.724 \\ 81-9-12 A & \text { Digit } & \text { Power } & 0.149 & 0.678 \\ 81-11-1 E & \text { Digit } & \text { Logarithmic } & 0.186 & 0.759 \\ 81-18-10 A & \text { Digit } & \text { Power } & 0.190 & 0.692 \\ 81-11-1 C & \text { Palm } & \text { Power } & 0.237 & 0.716 \\ 81-11-1 B & \text { Palm } & \text { Power } & 0.334 & 0.709\end{array}$

Rapidly adapting, steep relationship

$\begin{array}{lllll}81-35-3 A & \text { Digit } & \text { Power } & 0.559 & 0.804 \\ 81-36-9 A & \text { Digit } & \text { Power } & 0.629 & 0.964 \\ 81-25-14 A & \text { Digit } & \text { Power } & 0.689 & 0.983 \\ 81-34-12 A & \text { Digit } & \text { Power } & 0.938 & 0.982\end{array}$

Rapidly adapting, discontinuous relationship

$\begin{array}{lllll}81-25-5 A & \text { Digit } & \text { Linear } & 0.844 & 0.849 \\ 81-3-1 C & \text { Palm } & \text { Power } & 1.153 & 0.901\end{array}$

anits listed within category in increasing order of the value of $b$.

very similarly to those previously described at lower levels of the somatosensory system (B. H. Pubols and Warren, 1985). In all five cases, a power function provided the best fit. The median value of the power function exponent, $b$, was 0.682 , and the median value of $r$, used as an index of goodness-of-fit, was 0.978 .

The results for the RA units were less straightforward. A power function provided the best fit in 10 of the 12 cases, and a linear or logarithmic function provided the best fit once each in the remaining 2 cases. However, examination of the values of the power function exponent, $r$, as well as the shape of the functions, suggests that these RA units actually fall into three distinct groups. The velocity-discharge rate functions of six neurons were very flat, although monotonically increasing. The values of $b$ ranged from 0.146 to 0.334 , far lower than values found in either primary afferents or neurons of the main cuneate nucleus (B. H. Pubols and Warren, 1985). These six units also yielded the least reliable fits (lowest values of $r$ ). The second group of RA units $(N=4)$ behaved more like RA units observed elsewhere within the somatosensory system, the range of values of $b$ being $0.559-0.938$. The third category of RA units $(N=2)$ showed discontinuous functions. In these cases, the discharge rate remained relatively low and constant for velocities up to $5-10 \mu \mathrm{m} / \mathrm{msec}$, at which point the discharge rate jumped 5$20 \times$, showing little further change with additional increases in velocity. This discontinuous stimulus-response function has also been observed in cat VB neurons with glabrous skin RFs, where the discontinuitics are cven greater, with increments in spike discharge rate of 40-50 $\times$ (Kelahan and Pubols, unpublished observations). Although values of $b$ and $r$ are given in Table 3 for all 17 units, the concept of a power function has little meaning for the units with discontinuous functions. Examples of all three types of RA velocity-instantaneous frequency function flat, steep, and discontinuous-are shown in Figure 5. 


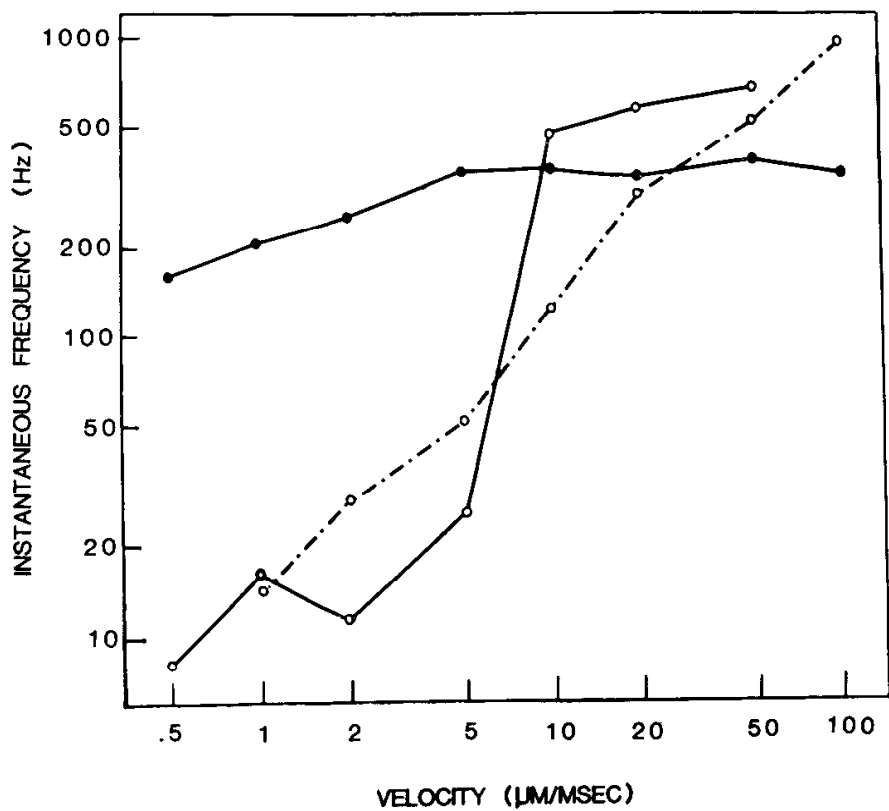

Figure 5. Mean instantaneous frequency (1000/mean interspike interval, in $\mathrm{msec}$ ) as a function of displacement ramp velocity for three RA units in VB. Open circles and dotted lines, Steep function $(b=0.938)$, also characteristic of RA units of both the cuneate nucleus and cuneate fasciculus. Solid circles and lines, Relatively flat relationship $(b=0.186)$, not seen at lower levels of the dorsal column-medial lemniscal system. Open circles, solid lines, Discontinuous function, also seen for the first time within VB.

\section{Neurons showing complex features}

As noted earlier, 10 neurons revealed novel properties that would not have been predicted from a knowledge of the properties of primary afferent fibers. Although these 10 neurons represent less than $7 \%$ of the total sample, this category may well be underrepresented, as others have reported larger percentages (see the introduction).

Four units showed a property found in a few neurons of the MCN (Rowinski et al., 1985), but that we have never observed in any of over 600 primary mechanoreceptive afferent fibers with RFs on the raccoon's forepaw (see B. H. Pubols and Pubols, 1983, for review). These four neurons had peripheral RFs encompassing both glabrous skin and adjacent hairy skin. The response to stimulation of any part of the RF was RA in all cases. Two were shown to bc TCR units by antidromic activation. In three instances, the RF was on one or more glabrous palm pads and adjacent hairy skin; in the fourth, the RF was on one of the digits. In no case were the RFs discontinuous.

Six additional neurons exhibited complex features not found at any lower level. One of these was a unit that behaved as if it were receiving SA input when ramp velocities were low, but RA input at higher ramp velocities. At velocities below $10 \mu \mathrm{m} / \mathrm{msec}$, the unit responded as an SA unit with an acceleration of discharge during ramp stimulation, but at higher velocities it responded as an RA unit, yielding 4-8 spikes/ramp, but with no responses during sustained displacement.

One unit had a large, bilateral receptive field, encompassing both glabrous and hairy skin (Fig. $6 A$ ). The RF included both the dorsal and ventral surfaces of the entire left (contralateral) arm, extended across the dorsum of the thorax, and down the left arm, stopping at the wrist. In addition to being activated by mechanical stimulation, which yielded an SA response, it could be orthodromically activated by electrical stimulation of the left median nerve and percutaneous electrical stimulation of the right arm. The unit was antidromically activated from the digit 4 subgyrus of SmI cortex, and this antidromic response

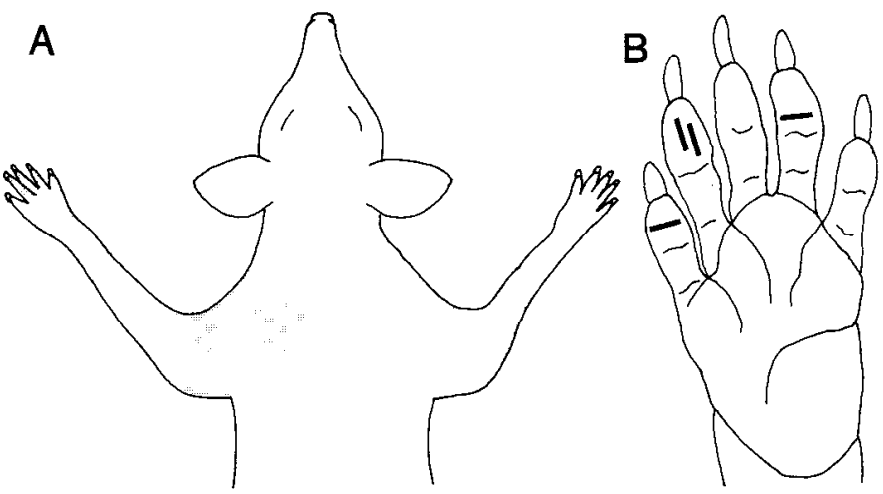

Figure 6. Examples of VB neurons exhibiting properties not seen at lower levels of the dorsal column-medial lemniscal system. $A$, Large bilateral $\mathrm{KF}$ including the entire contralateral forelimb, the dorsal trunk, and the dorsum of the ipsilateral forelimb, excluding wrist and forepaw. On the left side, both glabrous and hairy skin were included within the RF. $B$, Four linear orientation detectors, responding preferentially to a "tactile edge," oriented in the indicated directions. In two cases, the preferred orientation was parallel to the long axis of the digit, and in two it was perpendicular to the long axis.

could be blocked by collision via stimulation of the left median nerve. At least 60 units were evaluated for bilaterality of RF, but this was the only example found.

The remaining four VB neurons displayed properties of "tactile edge," or linear orientation, detectors (L. M. Pubols and Leroy, 1977). To examine these units, both elongated ("edge") and cylindrical stimulus probes were used (see Methods). The RFs of all four linear orientation detectors were located on digits (Fig. 6B). All displayed a resting discharge, which varied from unit to unit between ca. 1 and $25 \mathrm{~Hz}$. In all four cases, evoked responses were more vigorous to the tactile edge stimuli applied in one of the two orientations tested than to the edge applied in the other oricntation or to the cylindrical stimulus probe. In two cases, both on digit 2 , the preferred orientation was parallel to the long axis of the digit, while in the remaining two, one each on digits 1 and 4, the preferred orientation was perpendicular to the long axis. The response of the neuron with the digit 4 RF was $S A$, while the responses of the other three were $\mathrm{RA}$. In the case of the SA unit, the number of spikes elicited over the first $1 \mathrm{sec}$ of stimulation in the nonpreferred orientation was $70 \%$ of the number elicited by stimulation in the preferred orientation, while the number elicited by the rounded stimulus was $56 \%$ of the number elicited by edge stimulation in the preferred orientation. RA responses to stimulation in the nonpreferred orientation were $30-60 \%$ of those to the preferred orientation, and RA responses to the cylindrical stimulus were approximately $50 \%$ of the response to the preferred edge stimulus orientation. Thus, in all cases, the orientation selectivity of these neurons is not absolute, although each expresses a clear orientation preference.

\section{Discussion}

The research whose results are reported here is part of a larger project, the long-term goal of which is to add to our understanding of the tactile information-processing capabilities and limitations of various levels and nuclear regions of the mammalian somatic afferent system. The raccoon has been used as a model animal for the study of coding, transmission, and transformation of tactile information acquired by mechanoreceptors associated with a behaviorally salient tactile organ system, the hand, or forepaw. The use of comparable methodologies (for measuring absolute thresholds and receptive-field areas, and for assessing stimulus-response relationships, for example) at different nuclear regions enhances the validity of cross-level comparisons, 
and hence makes statements regarding convergences, divergences, and other types of interaction more meaningful. Single neurons have now been studied at a number of levels of the somatosensory system, from the level of primary afferent fibers through the thalamic ventrobasal complex (see B. H. Pubols and Pubols, 1983, and B. H. Pubols and Warren, 1985, for reviews), to primary somatosensory cortex (L. M. Pubols and Leroy, 1977).

\section{Response to electrical stimulation of cerebral cortex}

Of 61 units tested for activation from primary somatosensory cortex, 54 yielded an antidromic response. Thus, $88 \%$ of the tested sample could be classed as thalamocortical relay neurons. This figure compares favorably with the finding in raccoon, utilizing the retrograde HRP transport technique, that $80 \%$ of the large $(18-30 \mu \mathrm{m})$ cells within the appropriate VB subnucleus were labeled following injections of the corresponding cortical subgyrus (Warren and Pubols, 1984). Both sets of data are in general agreement with the widely obtained findings in cats, based on both electrophysiological (Anderson et al., 1964; Iwamura and Spencer, 1975; Tsumoto and Nakamura, 1974) and anatomical (Ralston and Sharp, 1973; Spreafico et al., 1983) methods, that the great majority of VB neurons are TCR cells (73-88\%).

\section{Classification of neurons by modality}

One feature of interest has been the relative representation of different receptor types at different levels of the somatosensory system. The proportions of RA and SA fibers are found to be roughly equal in both the median nerve (L. M. Pubols et al., 1971 ) and dorsal roots (L. M. Pubols and Pubols, 1973). Very few Pc units are found in the median nerve (B. H. Pubols, 1980); the great majority presumably travel centrally through deep nerves, for they represent approximately $26 \%$ of cutaneous fibers entering the spinal cord via the dorsal roots, and $13 \%$ of those ascending through the cuneate fasciculus (L. M. Pubols and Pubols, 1973). Within the cuneate fasciculus, the ratio of RA to SA fibers is approximately $3: 1$. Thus, there is a differential projection of $\mathrm{RA}$, as opposed to $\mathrm{SA}$, units into the cuneate fasciculus of the dorsal column-medial lemniscal system. The proportions of RA, SA, and Pc neurons are roughly comparable in the cuneate fasciculus and cuneate nucleus (Table 1; see also B. H. Pubols and Warren, 1985). However, the proportion of RA neurons increases significantly within VB. Although the changes as one enters the spinal cord might bc attributable to a sorting process whereby information arising from different receptor types ascends the spinal cord via different pathways (Brown, 1968; Petit and Burgess, 1968), such an explanation cannot account for differences between the cuneate and ventrobasal nuclei, as the thalamus represents a focus of convergence from many different ascending pathways, including the spinocervicothalamic and spinothalamic systems, as well as the dorsal column-medial lemniscal system (see Willis and Coggeshall, 1978 , for a review).

At least three possible explanations might be suggested for these differences in the proportions of RA, SA, and Pc units within the MCN and VB. First, it is possible that a greater proportion of TCR cells with SA or Pc properties contributes to the group of VB units with complex properties than the proportion of RA units. A second possibility is that differences in proportions may reflect the additional contributions from cervicothalamic, spinothalamic, descending, or other systems that converge upon VB. Finally, Gottschaldt et al. (1983) recently described a class of neuron within cat VB which, although receiving a tonic (SA) input, responds with a phasic (RA) output. If such neurons also exist within the raccoon $\mathrm{VB}$, they could contribute to the differences in proportions of RA and SA units found within the MCN and VB. These three possibilities are not necessarily mutually exclusive, and at present, there is no basis for choosing one over another.

Within the raccoon thalamus, we found that, although Pc neurons are localized deeply, RA and SA neurons are intermixed within the somatotopically appropriate region of VB (see Fig. 2). The location of Pc units deep within VB is consistent with recent findings by Fisher et al. (1983) on the location of cortically projecting Pc units in cats. However, the present results are at variance with reports by Dykes and associates in both squirrel monkey (Dykes et al., 1981; Kaas et al., 1984) and cat (Herron and Dykes, unpublished observations) that thalamic neurons with Pc properties are differentially localized within the nucleus ventralis posterior inferior (VPI). Clearly, the concept of submodality segregation, or grouping, does not apply for all submodalities represented within the raccoon thalamus.

The ratio of RA to SA neurons within raccoon primary somatosensory cortex is approximately what it is within VB ( $L$. M. Pubols and Leroy, unpublished observations). Current evidence suggests that in cats there is a preferential projection of Pacinian-derived information into the second somatosensory cortex (Bennett et al., 1980; Ferrington and Rowe, 1980; Herron and Dykes, unpublished observations). Thus, it would appear that modality properties of thalamic neurons, as well as modality segregation within the thalamus, is imposed in a relatively straightforward fashion upon somatosensory cortex.

\section{Absolute thresholds and receptive-field areas}

Although absolute displacement thresholds of ventrobasal RA units tended to be higher (median $=85 \mu \mathrm{m}$ ) than those of SA units (median $=35 \mu \mathrm{m}$ ), the differences were not statistically significant. The values obtained in VB are comparable to those found at lower levels of the raccoon dorsal column-medial lemniscal system, including both the main cuneate nucleus (Rowinski et al., 1985) and primary afferents of the cuneate fasciculus (B. H. Pubols and Pubols, 1973). Differences in absolute displacement thresholds of RA and SA units were not statistically significant at either of these levels. Thus it would appear that, at all levels of the raccoon dorsal column-medial lemniscal system, RA and SA thresholds are comparable.

The RF areas of VB neurons with RFs on palmar surfaces are significantly larger than are those of VB neurons with digital RFs (Table 2). In a preliminary report (B. H. Pubols and Warren, 1985) utilizing a subsample of $44 \mathrm{VB}$ units out of the total sample (81 units) described in the present paper, it was reported that both digital and palmar RF areas of VB neurons were, on average, $4 \times$ larger than those of the $\mathrm{MCN}$. The added units that complete the samples described here reduce these magnification factors to $3 \times$ for the digital RFs and $2 \times$ for the palmar RFs (comparisons of medians). However, this further emphasizes the asscrtion that spatial convergence is, by far, greater at the level of the MCN, where areal magnification factors are $40 \times$ for digital RFs and $100 \times$ for palmar RFs. Further, palmar RFs are significantly larger than digital RFs of cuneate neurons (Rowinski et al., 1981), but this is not the case with respect to primary afferents. Thus, there is greater spatial convergencc from afferents from the palm than from the digits, and greater spatial convergence at the cuneate than at the thalamic nuclear level. There appears to be no further increase in RF area for neurons of primary somatosensory cortex (Kelahan and Doetsch, 1984; L. M. Pubols and Leroy, 1977, and unpublished observations).

\section{Coding of displacement ramp velocity by ventrobasal neurons}

In order to make meaningful comparisons with lower levels of the raccoon dorsal column-medial lemniscal system, power functions were fitted to the relationship between displacement ramp velocity and instantaneous frequency during ramp stimulation (see Rowinski et al., 1985, for rationale and further 
references). At all three levels-the cuneate fasciculus (L. M. Pubols and Pubols, 1973), the cuneate nucleus (Rowinski et al., 1985), and the ventrobasal complex (present report)-exponents (b) of the power function, used as an index of sensitivity to differences in stimulus velocity, are quite consistent for SA units. At each level, the range in values of $b$ is small, and samples at each of the three levels do not differ significantly in values of $b$ (medians $=0.525,0.565$, and 0.682 , respectively).

The situation is far more complex with respect to the RA units. At all levels, there is greater interunit variability in values of $b$. Sensitivity of MCN neurons is significantly greater than that of cuneate fascicular neurons (medians $=0.948$ and 0.670 , respectively). Excluding the two VB neurons with discontinuous functions (see Results), the overall median for rapidly adapting VB units was 0.286 , significantly less than that for MCN units $(p<0.005)$. However, this comparison is an oversimplification, as the VB units may be partitioned into three distinct classes on the basis of their exponents and the shape of the function. Only one of these classes showed any resemblance to RA units at lower levels, the "steep relationship" group (see Table 3). The median value of $b$ of this group was 0.659 , comparable to that of primary afferents. However, the existence of the relatively flat functions, as well as of the discontinuous functions (Table 3 ; Fig. 5), suggests that quantitative information transmission by single VB elements is greatly reduced when compared with lower levels. The great interunit variability in displacement velocity thresholds, and cspccially thresholds for rcliablc coding of velocity, suggests an increased role for recruitment as a means of conveying information regarding stimulus velocity. As displacement velocity increases, there is an increase in discharge rate within at least some units; but in addition, the number of activated units increases.

\section{Ventrobasal neurons with complex properties}

Although this report has stressed ventrobasal neurons displaying modality and place-specificity - the classical "lemniscal" properties of Mountcastle (e.g., Rose and Mountcastle, 1959)-it is apparent that there are a number of types of neurons found within VB that display different, more complex, properties. Perhaps the most elementary of these properties is the submodality convergence represented by the existence of neurons whose receptive fields include both glabrous and hairy skin. Such neurons apparently make their first appearance within the dorsal column nuclei of both raccoon (Rowinski et al., 1985) and cat (Bystrzycka et al., 1977; R. E. W. Fyffe, S. Cheema, A. R. Light, and A. Rustioni, unpublished observations), and have been observed in large numbers in the medial lemniscus of the cat (Brown et al., 1974). They have previously been described in the cat VB (e.g., Golovchinsky et al., 1976), as well as the racoon SmI cortex (Kelahan and Doetsch, 1984). The most exaggerated example of this type of submodality convergence is represented in the present report by the neuron with the large bilateral RF encompassing both glabrous and hairy skin (Fig. 6A).

The most interesting class of VB neuron displaying complex properties is the class identified in somatosensory cortex as "feature detectors" (Werner and Whitsel, 1973). In somatosensory cortex, feature detector neurons include those (1) responding preferentially to "tactile edges," oriented in a particular direction on the skin rather than to punctate stimuli (Hyvärinen and Poranen, 1978; L. M. Pubols and Leroy, 1977), responding preferentially to a stimulus moving across the skin in a particular direction (Costanzo and Gardner, 1980; Hyvärinen and Poranen, 1978; Whitsel et al., 1972; S. Warren, H. A. Hämäläinen, and E. P. Gardner, unpublished observations), and (3) responding only, or optimally, to particular three-dimensional stimulus configurations (Iwamura and Tanaka, 1978).

It is clear from the present results, as well as from previously published observations, that feature detection is also a property of a small population of ventrobasal neurons. Ventrobasal movement detectors have already been described in cats (Golovchinsky et al., 1981; Gordon and Manson, 1967), and the present results confirm the existence of tactile edge detectors as well. Although ventrobasal linear orientation detectors comprised less than $3 \%$ of our total sample, in raccoon SmI cortex, they may represent as much as $40 \%$ of the total neuronal population (L. M. Pubols and Leroy, 1977). It is apparent, then, that the synthesis of stimulus parameters which yields tactile perceptions, although predominantly a cortical function, has its beginnings within the thalamus.

\section{General conclusions}

The concept that properties of one level of the somatosensory system, including properties of single neuronal elements within that level, are, at least in part, imposed by properties of lower levels of the system was clearly enunciated at least as early as 1938 by Woodburne and Crosby (Woodburne and Crosby, 1938), and this is now a generally recognized principle (Mountcastle, 1980). It has received its most recent and explicit application in the work of Jones and co-workers on the ventrobasal thalamic substrate for modality and place-specific cell columns in primate somatosensory cortex (Jones, 1981; Jones and Friedman, 1982; Jones et al., 1982).

Certainly, many of the findings of the present series of investigations, discussed above, are in agreement with this principle. These findings, based on the use of comparable methodologies as applied to the study of single neurons at several levels of the somatosensory system - all such neurons activated by light mechanical stimulation of the glabrous skin of the raccoon's forepaw - reveal, however, that within this broad framework, systematic changes may occur from one level to the next. Among these changes are the following: (1) Although the majority of neurons at each level possess the properties of modality and place-specificity, behaving as if they receive input from a single type of cutaneous mechanoreceptor (RA, SA, Pc), the proportions of each may change from level to level, most notably in going from cuneothalamic to thalamocortical neurons. (2) Receptive-field areas of single neurons reveal the greatest enlargement as cuneate fascicular fibers converge on single neurons of the main cuneate nucleus; there is a lesser increase in RF size of ventrobasal neurons, and probably no further increment at the level of primary somatosensory cortex. (3) Changes occur, from level to level, in the sensitivity of individual neurons to velocity of skin indentation, and, at the thalamic level, the recruitment principle appears to take on added significance at the expense of reliable frequency coding, at least by rapidly adapting single neurons.

Welker (1973) has stressed the very important point that the thalamic ventrobasal complex is not merely a one-way station in an ascending pathway, but is, rather, part of a complex circuit that receives both ascending and descending inputs and is, itself, linked with other neural circuits. Tactile information ascending through somatic afferent pathways must ultimately reach the cerebral cortex and contribute to the perceptions that provide both information about the somatosensory environment, and the substrate for adaptive behavioral interaction with the environment. Because of the crucial location and the nature of its input and output circuitry, the thalamic ventrobasal complex is ideally situated to play a major role in these processes. As Welker (1973, p. 314) has pointed out, "As a whole, the total cell population [of VB] potentially can respond to all known stimulus features that an animal can respond to behaviorally. ... Stimulus features coded by VB neurons are so specific that only circuits involving VB are able to represent the body image accurately and discriminate between delicate and complex spatiotemporal patterns of somatic sensory stimuli." 


\section{References}

Anderson, P., J. C. Eccles, and T. A. Sears (1964) The ventro-basal complex of the thalamus: Types of cells, their responses and their functional organization. J. Physiol. (Lond.) 174: 370-399.

Bennett, R. E., D. G. Ferrington, and M. Rowe (1980) Tactile neuron classes within second somatosensory area (SII) of cat cerebral cortex. J. Neurophysiol. 43: 292-309.

Berkeley, K. J. (1973) Response properties of cells in ventrobasal and posterior group nuclei of the cat. J. Neurophysiol. 36: 940-952.

Brown, A. G. (1968) Cutaneous afferent fibre collaterals in the dorsal columns of the cat. Exp. Brain Res. 5: 293-305.

Brown, A. G., G. Gordon, and R. H. Kay (1974) A study of single axons in the cat's medial lemniscus. J. Physiol. (Lond.) 236: 225246.

Bystrzycka, E., B. S. Nail, and M. Rowe (1977) Inhibition of cuneate neurones: Its afferent source and influence on dynamically sensitive "tactile" neurones. J. Physiol. (Lond.) 268: 251-270.

Chubbuck, J. G. (1966) Small motion biological stimulator. Appl. Phys. Lab. Tech. Digest 5: 18-23.

Costanzo, R. M., and E. P. Gardner (1980) A quantitative analysis of response of direction-sensitive neurons of somatosensory cortex of awake monkeys. J. Neurophysiol. 43: 1319-1341.

Dykes, R. W., M. Sur, M. M. Merzenich, J. H. Kaas, and R. J. Nelson (1981) Regional segregation of neurons responding to quickly adapting, slowing adapting, deep and pacinian receptors within thalamic ventroposterior lateral and ventroposterior inferior nuclei in the squirrel monkey (Saimiri sciureus). Neuroscience 6: 1687-1692.

Ferrington, D. G., and M. Rowe (1980) Differential contributions to coding of cutaneous vibratory information by cortical somatosensory areas I and II. J. Neurophysiol. 43: 310-331.

Fisher, G. R., B. Freeman, and M. J. Rowe (1983) Organization of parallel projections from Pacinian afferent fibers to somatosensory cortical areas I and II in the cat. J. Neurophysiol. 49: 75-97.

Golovchinsky, V., L. Kruger, S. Saporta, B. E. Stein, and D. W. Young (1976) Convergent somatic input onto neurons of the ventrobasal complex of the cat. Neurosci. Abstr. 2: 936.

Golovchinsky, V., L. Kruger, S. Saporta, B. E. Stein, and D. W. Young (1981) Properties of velocity-mechanosensitive neurons of the cat ventrobasal thalamic nucleus with special reference to the concept of convergence. Brain Res. 209: 355-374.

Gordon, G., and J. R. Manson (1967) Cutaneous receptive fields of single nerve cells in the thalamus of the cat. Nature 215: 597-599.

Gottschaldt, K.-M., C. Vahle-Hinz, and T. P. Hicks (1983) Electrophysiological and micropharmacological studies on mechanisms of input-output transformation in single neurones of the somatosensory thalamus. In Somatosensory Integration in the Thalamus, G. Macchi, A. Rustioni, and R. Spreafico, eds., pp. 199-216, Elsevier, Amsterdam.

Haring, J. H., M. J. Rowinski, and B. H. Pubols (1984) Electrophysiology of raccoon cuneocerebellar neurons. Somatosensory Res. 1: $247-264$

Herron, P. (1983) The connections of cortical somatosensory areas I and II with separate nuclei in the ventroposterior thalamus in the raccoon. Neuroscience 8: 243-257.

Hyvärinen, J., and A. Poranen (1978) Movement-sensitive and direction and orientation selective cutaneous receptive fields in the hand area of the post-central gyrus in monkeys. J. Physiol. (Lond.) 283 : 523-537.

Iggo, A., and H. Ogawa (1977) Correlative physiological and morphological studies of rapidly adapting mechanoreceptors in cat's glabrous skin. J. Physiol. (Lond.) 266: 275-296.

Iwamura, Y., and W. A. Spencer (1975) Functional connections of cutaneous thalamocortical relay cells within the ventrobasal complex of cat. In The Somatosensory System, H. H. Kornhuber, ed., pp. 270276, Georg Thieme, Stuttgart.

Iwamura, Y., and M. Tanaka (1978) Postcentral neurons in hand region of area 2: Their possible role in the form discrimination of tactile objects. Brain Res. 150: 662-666.

Jabbur, S. J., M. A. Baker, and A. L. Towe (1972) Wide-field neurons in thalamic nucleus ventralis posterolateralis of the cat. Exp. Neurol. 36: 213-238.

Jones, E. G. (1981) Anatomy of cerebral cortex: Columnar inputoutput organization. In The Cerebral Cortex, F. O. Schmidt, F. G.
Worden, G. Adelman, and M. Dennis, eds., pp. 199-235, MIT Press, Cambridge, MA.

Jones, E. G., and D. P. Friedman (1982) Projection pattern of functional components of thalamic ventrobasal complex on monkey somatosensory cortex. J. Neurophysiol. 48: 521-544.

Jones, E. G., D. P. Friedman, and S. H. C. Hendry (1982) Thalamic basis of place- and modality-specific columns in monkey somatosensory cortex: A correlative anatomical and physiological study. J. Neurophysiol. 48: 545-568.

Kaas, J. H., R. J. Nelson, M. Sur, R. W. Dykes, and M. M. Merzenich (1984) the somatotopic organization of the ventroposterior thalamus of the squirrel monkey Saimiri sciureus. J. Comp. Neurol. 226:111140.

Kelahan, A. M., and Doetsch, G. S. (1984) Time-dependent changes in the functional organization of somatosensory cortex following digit amputation in adult raccoons. Somatosensory Res. 2: 49-81.

Knibestöl, M. (1973) Stimulus-response functions of rapidly adapting mechanoreceptors in the human glabrous skin area. J. Physiol. (Lond.) 232: 427-452

Lyall-Watson, M. (1963) A critical re-examination of food "washing" behaviour in the raccoon (Procyon lotor Linn.). Proc. Zool. Soc. Lond. 141: 371-393.

Mountcastle, V. B. (1967) The problem of sensing and the neural coding of sensory events. In The Neurosciences: $A$ Study Program G. C. Quarton, T. Melnechuk, and F. O. Schmidt, eds., pp. 393-408, Rockefeller University, N.Y.

Mountcastle, V. B. (1980) Medical Physiology, 14th Ed., Chap. 12, C V. Mosby, St. Louis, MO.

Petit, D., and P. R. Burgess (1968) Dorsal column projection of receptors in cat hairy skin supplied by myelinated fibers. J. Neurophysiol. 31: 849-855.

Poggio, G. F., and V. B. Mountcastle (1963) The functional properties of ventrobasal thalamic neurons studied in unanesthetized monkeys J. Neurophysiol. 26: 775-806.

Pubols, B. H. (1980) On- versus off- responses of raccoon glabrous skin rapidly adapting cutaneous mechanoreceptors. J. Neurophysiol. 43: $1558-1570$.

Pubols, B. H., and L. M. Pubols (1976) Coding of mechanical stimulus velocity and indentation depth by squirrel monkey and raccoon glabrous skin mechanoreceptors. J. Neurophysiol. 39: 773-787.

Pubols, B. H., and L. M. Pubols (1983) Tactile receptor discharge and mechanical properties of glabrous skin. Fed. Proc. 42: 2528-2535.

Pubols, B. H., and S. Warren (1985) Information processing within the raccoon somatosensory system. In Development, Organization, and Processing in Somatosensory Pathways, M. J. Rowe and W. D. Willis, eds., pp. 183-189, Alan R. Liss, New York.

Pubols, L. M., and R. F. Ierny (1977) Orientation detectors in the primary somatosensory neocortex of the raccoon. Brain Res. 129:6174.

Pubols, L. M., and B. H. Pubols (1973) Modality composition and functional characteristics of dorsal column mechanoreceptive afferent fibers innervating the raccoon's forepaw. J. Neurophysiol. 36: 10231037.

Pubols, L. M., B. H. Pubols, and B. L. Munger (1971) Functional properties of mechanoreceptors in glabrous skin of the raccoon's forepaw. Exp. Neurol. 31: 165-182.

Ralston, H. J., and P. V. Sharp (1973) The identification of thalamocortical relay cells in the adult cat by means of retrograde axonal transport of horseradish peroxidase. Brain Res. 62: 273-278

Rose, J. E., and V. B. Mountcastle (1959) Touch and kinesthesis. In Handhook of Physiology, Section 1, Neurophysiology, Vol. 1. J. Field, H. W. Magoun, and V. E. Hall, eds., pp. 387-429, American Physiological Society, Washington, DC

Rowinski, M. J, J. H. Haring, and B. H. Pubols (1981) Correlation of peripheral receptive field area and rostrocaudal locus of neurons within the raccoon cuneate nucleus. Brain Res. 211: 463-467.

Rowinski, M. J., J. H. Haring, and B. H. Pubols (1985) Response properties of raccoon cuneothalamic neurons. Somatosens. Res. 2: $263-280$.

Spreafico, R., D. E. Schmechel, L. C. Ellis, and A. Rustioni (1983) Cortical relay neurons and interneurons in the $n$. ventralis posterolateralis of cats: A horseradish peroxidase, electron microscopic, Golgi and immunocytochemical study. Neuroscience 9: 491-507.

Tsumoto, T., and S. Nakamura (1974) Inhibitory organization of the 
thalamic ventrobasal neurons with different periphcral representations. Exp. Brain Res. 21: 195-210.

Warren, S., and B. H. Pubols (1984) Somatosensory thalamocortical connections in the raccoon: An HRP study. J. Comp. Neurol. 227: 597-606.

Welker, W. I. (1973) Principles of organization of the ventrobasal complex in mammals. Brain Behav. Evol. 7: 253-336.

Welker, W. I., and J. I. Johnson (1965) Correlation between nuclear morphology and somatotopic organization in ventrobasal complex of the raccoon's thalamus. J. Anat. 99: 761-790.

Welker, W. I., and S. Seidenstein (1959) Somatic sensory representation in the cerebral cortex of the raccoon (Procyon lotor). J. Comp. Neurol. 111: 469-502.

Welker, W. I., J. I. Johnson, and B. H. Pubols (1964) Some morpho- logical and physiological charactcristics of the somatic sensory system in raccoons. Am. Zool. 4: 75-94.

Werner, G., and B. L. Whitsel (1973) Functional organization of the somatosensory cortex. In Handbook of Sensory Physiology: II. Somatosensory System, A. Iggo, ed., pp. 621-700, Springer-Verlag, Berlin.

Whitsel, B. L., J. R. Roppolo, and G. Werner (1972) Cortical information processing of stimulus motion on primate skin. J. Neurophysiol. 35: 691-717.

Willis, W. D., and R. E. Coggeshall (1978) Sensory Mechanisms of the Spinal Cord, Plenum, New York.

Woodburne, R. T., and E. C. Crosby (1938) The basis of cortical localization. Anat. Rec. 70: 84 (Abstract). 